Pacific Journal of Mathematics

INTERSECTION HOMOLOGY OF WEIGHTED PROJECTIVE 


\title{
INTERSECTION HOMOLOGY OF WEIGHTED PROJECTIVE SPACES AND PSEUDO-LENS SPACES
}

\author{
Masato Kuwata
}

In this paper we calculate the integral intersection homology groups of weighted projective spaces and pseudo-lens spaces. Most computations of intersection homology have been for the rational groups. The groups calculated here have interesting torsion.

1. Introduction. Let $b=\left(b_{0}, \ldots, b_{n}\right)$ be an $(n+1)$-tuple of positive integers. The weighted projective space is by definition

$$
\mathbf{P}_{n}\left(b_{0}, \ldots, b_{n}\right)=\left\{\left(z_{0}, \ldots, z_{n}\right) \in \mathbf{C}^{n+1}-\{0\}\right\} / \sim
$$

where $\left(z_{0}, \ldots, z_{n}\right) \sim\left(\lambda^{b_{0}} z_{0}, \ldots, \lambda^{b_{n}} z_{n}\right), \lambda \in \mathbf{C}^{\times}=\mathbf{C}-\{0\}$.

Let $b^{\prime}=\left(b_{1}, \ldots, b_{n}\right)$. The pseudo-lens space is by definition

$$
L_{n}\left(b_{0} ; b_{1}, \ldots, b_{n}\right)=\left\{\left.\left(z_{1}, \ldots, z_{n}\right) \in \mathbf{C}^{n}\left|\sum_{i=1}^{n}\right| z_{i}\right|^{2}=1\right\} / \sim
$$

where $\left(z_{1}, \ldots, z_{n}\right) \sim\left(\zeta^{b_{1}} z_{1}, \ldots, \zeta^{b_{n}} z_{n}\right), \zeta \in \mathbf{Z} / b_{0} \subset \mathbf{C}^{\times}$.

Note that $\mathbf{P}_{n}\left(b_{0}, \ldots, b_{n}\right)$ is naturally identified with $\mathbf{P}_{n}\left(r b_{0}, \ldots, r b_{n}\right)$. Furthermore, if $\left(r, b_{i}\right)=1, \mathbf{P}_{n}\left(r b_{0}, \ldots, b_{i}, \ldots, r b_{n}\right)$ is identified with $\mathbf{P}_{n}\left(b_{0}, \ldots, b_{n}\right)$ via the map $\left[z_{0}, \ldots, z_{n}\right] \mapsto\left[z_{0}, \ldots, z_{i}, \ldots, z_{n}\right]$. Also, $L_{n}\left(b_{0} ; r b_{1}, \ldots, r b_{n}\right) \cong L_{n}\left(b_{0} ; b_{1}, \ldots, b_{n}\right)$, and $L_{n}\left(b_{0} ; b_{1}, \ldots, b_{n}\right) \cong$ $L_{n}\left(b_{0} ; r b_{1}, \ldots, b_{i}, \ldots, r b_{n}\right)$ if $\left(r, b_{i}\right)=1(i=1, \ldots, n)$. Thus, we may assume $\operatorname{gcd}\left(b_{0}, \ldots, \breve{b}_{i}, \ldots, b_{n}\right)=1$ for all $i$.

Since both weighted projective spaces and pseudo-lens spaces are rational homology manifolds, intersection homology of these spaces with rational coefficients is isomorphic to ordinary rational homology, which is the same as the homology of ordinary projective space or the ordinary sphere. Thus our focus goes to torsion phenomena in intersection homology, which are much more complicated than torsion phenomena of ordinary homology and not yet well understood.

We first discuss the intersection homology of pseudo-lens spaces, then we will determine the intersection homology of weighted projective spaces by using the results about pseudo-lens spaces. We also 
determine the Goresky-Siegel invariant which indicates how much Poincaré duality fails over integers.

The author would like to express his sincere gratitude to Professors A. Hattori, M. Masuda, M. Goresky, and R. MacPherson for their helpful suggestions.

2. Preliminaries. In order to calculate intersection homology, we first stratify $\mathbf{P}_{n}(b)$ and $L_{n}\left(b_{0} ; b^{\prime}\right)$. Let $p$ be a prime number. Decompose each $b_{i}$ into primes:

$$
b_{i}=\prod_{p: \text { prime }} p^{\alpha_{p .1}} \quad i=1, \ldots, n .
$$

Define the index $i_{p}(k) \in\{0,1, \ldots, n\}, 0 \leq k \leq n$, so that we have

$$
\alpha_{p, i_{p}(0)} \geq \alpha_{p, i_{p}(1)} \geq \cdots \geq \alpha_{p, i_{p}(n-1)}=\alpha_{p, i_{p}(n)}=1 .
$$

We also define $j_{p}(k) \in\{1,2, \ldots, n\}, 1 \leq k \leq n$, such that

$$
\alpha_{p, j_{p}(1)} \geq \alpha_{p, j_{p}(2)} \geq \cdots \geq \alpha_{p, j_{p}(n-1)}=\alpha_{p, j_{p}(n)}=1 \text {. }
$$

Define:

$$
\begin{array}{r}
X_{2 n-2}(p) \\
\quad=\left\{\left[z_{0}, \ldots, z_{n}\right] \in \mathbf{P}_{n}(b) \mid z_{i_{p}(n)}=z_{i_{p}(n-1)}=\cdots=z_{i_{p}(n-l-1)}=0\right\} \\
2 \leq l \leq n
\end{array}
$$

Note that $\bar{X}_{2 n-2 l}(p)$ is homeomorphic to

$$
\mathbf{P}_{n}\left(b_{i_{p}(n)}, b_{i_{p}(n-1)}, \ldots, b_{i_{p}(n-l-1)}\right) .
$$

Now we define the stratification of $\mathbf{P}_{n}(b)$ as follows:

$$
\begin{aligned}
& X_{2 n}=\mathbf{P}_{n}(b), \\
& X_{2 n-2 l}=\bigcup_{p: \text { prime }} X_{2 n-2 l}(p), \quad 2 \leq l \leq n-1, \\
& X_{2 n-2 l-1}=X_{2 n-2 l}, \quad 2 \leq l \leq n-1, \\
& X_{2 n-1}=X_{2 n-2}=X_{2 n-3}=X_{2 n-4} .
\end{aligned}
$$

Also define:

$$
Y_{2 n-2 l-1}=\left\{\begin{array}{l}
\left\{\left[z_{1}, \ldots, z_{n}\right] \in L_{n}\left(b_{0} ; b^{\prime}\right) \mid z_{j_{p}(n)}=\cdots=z_{j_{p}(n-l-1)}=0\right\} \\
\varnothing \quad \text { if }\left(p, b_{0}\right)=1 .
\end{array}\right.
$$


$\bar{Y}_{2 n-2 l-1}(p)$ is homeomorphic to $L_{n}\left(d ; b_{i_{p}(n-l-1)}, \ldots, b_{i_{p}(n)}\right)$, where $d=\operatorname{gcd}\left(b_{i_{p}(0)}, \ldots, b_{i_{p}(n-l)}\right)$. Define the stratification of $L_{n}\left(b_{0} ; b^{\prime}\right)$ as follows:

$$
\begin{aligned}
& Y_{2 n}=\mathbf{P}_{n}(b), \\
& Y_{2 n-2 l-1}=\bigcup_{p: \text { prime }} Y_{2 n-2 l-1}(p), \quad 2 \leq l \leq n-1, \\
& Y_{2 n-2 l-2}=Y_{2 n-2 l-1}, \quad 2 \leq l \leq n-1, \\
& Y_{2 n-1}=Y_{2 n-2}=Y_{2 n-3}=Y_{2 n-4} .
\end{aligned}
$$

LEMma 2.1. (i) Suppose $x$ is contained in $X_{2 n-2 l}(p)$. Then the link of the stratum $L_{x}$ at $x$ is homeomorphic to $L_{n}\left(d ; b_{i_{p}(n-l-1)}, \ldots, b_{i_{p}(n)}\right)$, where $d=\operatorname{gcd}\left(b_{i_{p}(0)}, \ldots, b_{i_{p}(n-l)}\right)$. Furthermore, the tubular neighborhood of $X_{2 n-2 l}(p)$ is isomorphic to $X_{2 n-2 l}(p) \times \operatorname{Cone}\left(L_{x}\right)$.

(ii) Suppose $x$ is contained in $Y_{2 n-2 l-1}(p)$. Then the link of the stratum $L_{x}$ at $x$ is homeomorphic to $L_{n}\left(d^{\prime} ; b_{j_{p}(n-l-1)}, \ldots, b_{j_{p}(n)}\right)$, where $d^{\prime}=\operatorname{gcd}\left(b_{j_{p}(0)}, \ldots, b_{j_{p}(n-l)}\right)$. Furthermore, the tubular neighborhood of $Y_{2 n-2 l}(p)$ is isomorphic to $Y_{2 n-2 l}(p) \times \operatorname{Cone}\left(L_{x}\right)$.

Proof. The proof is elementary and we omit it.

3. Intersection homology of pseudo-lens spaces. To state our result, we introduce some notation. A perversity $\bar{p}=(p(2), \ldots, p(n-2))$ is said to be a two-step perversity if $p(2 l) \equiv 0 \bmod 2$ for all $l \geq 1$. The associated two-step perversity $\bar{p}^{a}$ of $\bar{p}$ is the one defined by

$$
p^{a}(c)= \begin{cases}2\left[\frac{p(c)}{2}\right], & c=2 l, \\ {[p(c-1)]+[p(c+1)],} & c=2 l+1, \\ p(n), & c=2 l+1=n .\end{cases}
$$

We define $m_{p}(k)=\max \left(\alpha_{p, 0}-\alpha_{p, j_{p}(k)}\right)$.

By $A(n, j, k)(1 \leq k \leq n-1)$ we denote the point on the plane whose coordinates are $(2 n-k+1,2 n-2 j+1)$ and by $B(n, j, k)(1 \leq k \leq n-j)$ the point whose coordinates are $(2 n-2 k+1,2 n-2 j-2 k)$. The graph of a two-step perversity $\bar{p}$ passes through one and only one of the $A(n, j, k)$ 's or $B(n, j, k)$ 's. Finally we define the perversity $\bar{p}-2$ as $(p(4)-2, p(5)-2, \ldots, p(n-2)-2)$ when $p(4) \geq 2$.

THeOREM 3.1. Let $L_{n}=L_{n}\left(b_{0} ; b^{\prime}\right)$ be the pseudo-lens space and $\bar{p}$ be any perversity. Then

$$
I H_{*}^{\bar{p}}\left(L_{n}\right) \cong I H_{*}^{\bar{p}^{a}}\left(L_{n}\right) .
$$


Suppose the associated two-step perversity $\bar{p}^{a}$ passes through $A\left(n, j, k_{j}\right)$ or $B\left(n, j, k_{j}\right)$, then

$$
I H_{i}^{\bar{p}^{a}}\left(L_{n}\right)= \begin{cases}\mathbf{Z}, & i=0,2 n-1, \\ \mathbf{Z} / m_{j}, & i=2 j-1,1 \leq j \leq n, \\ 0, & \text { otherwise. }\end{cases}
$$

where $m_{j}=\prod_{p: \text { prime }} p^{m_{p}\left(k_{j}\right)}(1 \leq j \leq n)$.

Proof. We proceed by inducting on $n$. Choose a prime number $p$ and fix it once and for all. Let $L_{n-1}(p)=\bar{Y}_{2 n-3}(p)$. We claim the following three assertions:

$(1)_{n} I H_{*}^{\bar{p}}\left(L_{n}\right) \cong I H_{*}^{\bar{p}^{a}}\left(L_{n}\right)$,

$(2)_{n} I H_{2 i}^{\bar{p}}\left(L_{n}\right)=0, \quad i<2 n-3$,

$(3)_{n}$ If $p(4) \geq 2$, the map $I H_{i}^{\bar{p}-2}\left(L_{n-1}(p)\right) \otimes \mathbf{Z}_{p} \rightarrow I H_{i}^{\bar{p}}\left(L_{n}\right) \otimes \mathbf{Z}_{p}$ induced by the inclusion is an isomorphism for $i<2 n-3$, where $\mathbf{Z}_{p}$ is the ring of $p$-adic integers.

Assume these are true for the moment. From $(1)_{n}$ we may assume $\bar{p}$ is a two-step perversity. From $(2)_{n} L_{n}\left(b_{0} ; b^{\prime}\right)$ is $\bar{p}$-locally torsion free in the sense of Goresky-Siegel when $\bar{p}$ is a two-step perversity (cf. [GS]). Therefore the universal coefficient theorem holds for intersection homology; i.e.

$$
\begin{gathered}
I H_{i}^{\bar{p}}\left(L_{n}\right) \cong \operatorname{Hom}\left(I H_{2 n-i-1}^{\bar{t}-\bar{p}}\left(L_{n}\right), \mathbf{Z}\right) \oplus \operatorname{Ext}\left(I H_{2 n-i-2}^{\bar{t}-\bar{p}}\left(L_{n}\right), \mathbf{Z}\right), \\
I H_{i}^{\bar{p}}\left(L_{n} ; G\right) \cong I H_{i}^{\bar{p}}\left(L_{n}\right) \oplus \operatorname{Tor}\left(I H_{i-1}^{\bar{p}}\left(L_{n}\right), G\right) .
\end{gathered}
$$

This reduces the problem; we now only have to show

$$
I H_{i}^{\bar{p}}\left(L_{n} ; \mathbf{Z}_{p}\right)= \begin{cases}\mathbf{Z}_{p} / p^{m_{p}\left(k_{j}\right)}, & i=2 j-1,1 \leq j \leq n, \\ 0, & i=2 j, 1 \leq j \leq n\end{cases}
$$

for all two-step perversities such that $p(4)=2$ and for all prime numbers $p$. If $p(4)<2$, the theorem follows from the universal coefficient theorem and the fact that if $\bar{p}$ passes through $A\left(n, j, k_{j}\right)$ or $B\left(n, j, k_{j}\right)$, the perversity $\bar{t}-\bar{p}$ passes through $B\left(n, n-j, k_{j}\right)$ or $A\left(n, n-j, k_{j}\right)$ respectively. By induction (3) $n$ establishes the calculation because of the fact that if $\bar{p}$ passes through $A\left(n, j, k_{j}\right)$ or $B\left(n, j, k_{j}\right), \bar{p}-2$ passes through $A\left(n-1, j, k_{j}\right)$ or $B\left(n-1, j, k_{j}\right)$ respectively and $m_{p}\left(k_{j}\right)$ for $L_{n-1}$ is equal to the one for $L_{n}$.

Now we prove $(1)_{n}$ to $(3)_{n}$. When $n=1$, these are trivial. Assume $(1)_{k}$ to $(3)_{k}$ are true for all $k$ less than $n$. Consider the obstruction sequence (cf. [GM2; §5.5]); 


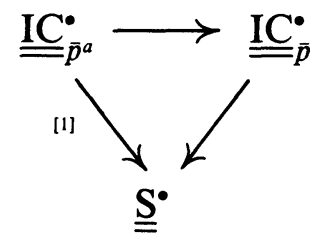

$\underline{\underline{\mathrm{H}}}^{-i}\left(\underline{\underline{\mathbf{S}}}^{\bullet}\right)_{x}=0$ unless $x \in X_{n-2 l}-X_{n-2 l-1}$ and $p(2 l)>p^{a}(2 l)$, in which case

$$
\underline{\underline{\mathrm{H}}}^{-i}\left(\underline{\underline{\mathbf{S}}}^{\bullet}\right)_{x}= \begin{cases}\underline{\underline{\mathrm{H}}}^{-i}\left(\underline{\underline{\mathrm{IC}}}_{\bar{p}}^{\bullet}\right)_{x}, & i=(2 n-1)-p(2 l) . \\ 0, & i \neq(2 n-1)-p(2 l) .\end{cases}
$$

On the other hand, $\underline{\underline{\mathrm{H}}}^{-(2 n-1)+p(2 l)}\left(\underline{\underline{\mathrm{IC}}}_{\bar{p}}^{*}\right)_{x} \cong I H_{2 l-p(2 l)-1}^{\bar{p}}\left(L_{x}\right)$ where $L_{x}$ is the link of the stratum containing $x$, which is a pseudo-lens space of dimension less than $2 n-1$. By definition of $\bar{p}^{a}, p(2 l)>p^{a}(2 l)$ only when $p(2 l)$ is odd. Therefore $2 l-p(2 l)-1$ is even, and from the induction assumption $I H_{2 l-p(2 l)-1}^{\bar{p}}\left(L_{x}\right)=0$. As a result, $\underline{\underline{\mathbf{H}}}^{\bullet}\left(\underline{\underline{\mathrm{S}}}^{\bullet}\right)_{x}=0$ everywhere, and thus $\underline{\underline{\mathbf{S}}}^{\bullet}=0$ in $D^{b}\left(L_{x}\right)$. This proves $(1)_{n}$.

Now we go to $(2)_{n}$ and $(3)_{n} . L_{n-1}(p)$ is stratified by $Y_{2 n-k} \cap$ $L_{n-1}, 0 \leq k \leq 2 n-3$. The codimension of the stratum $Y_{2 n-k} \cap$ $L_{n-1}$ is $k-2$. With respect to this stratification of $L_{n-1}(p)$, a $(\bar{p}, i)-$ allowable chain in $L_{n}$ with support in $L_{n-1}(p)$ is a $(\bar{p}-2, i)$-allowable chain in $L_{n-1}(p)$, and vice versa. In other words, the inclusion map $j: L_{n-1}(p) \rightarrow L_{n}$ induces $I C_{i}^{\bar{p}-2}\left(L_{n-1}(p)\right) \rightarrow I C_{i}^{\bar{p}}\left(L_{n}\right)$ and thus in-

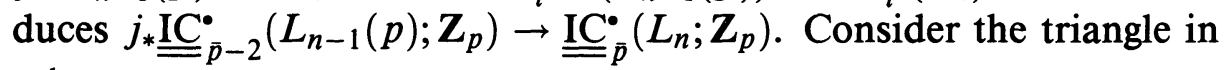
$D^{b}\left(L_{n}\right)$ :

$$
R j_{*}{\underline{\underline{\mathrm{IC}^{\circ}}}}_{\bar{p}-2}^{*}\left(L_{n-1}(p) ; \mathbf{Z}_{p}\right) \longrightarrow \underline{\underline{\underline{\mathrm{A}}}}_{\bar{p}}^{*}\left(\mathbf{Z}_{p}\right)
$$

For each $x$ in $L_{n}$, we have a long exact sequence of stalks associated to the triangle above:

$$
\begin{aligned}
\cdots \rightarrow \underline{\underline{\mathrm{H}}}^{-i-1}\left(\underline{\underline{\mathrm{A}}}_{\bar{p}-2}^{\cdot}\left(\mathbf{Z}_{p}\right)\right)_{x} \rightarrow \underline{\underline{\mathrm{H}}}^{-i}\left(R j_{*} \underline{\underline{\mathrm{IC}}}_{\bar{p}-2}^{\cdot}\left(L_{n-1}(p) ; \mathbf{Z}_{p}\right)\right)_{x} \rightarrow \\
\underline{\underline{\mathrm{H}}}^{-i}\left(\underline{\underline{\underline{\mathrm{IC}}}} \overline{\bar{p}}\left(L_{n} ; \mathbf{Z}_{p}\right)\right)_{x} \rightarrow \underline{\underline{\mathrm{H}}}^{-i}\left(\underline{\underline{\mathrm{A}}}_{\bar{p}}^{\cdot}\left(\mathbf{Z}_{p}\right)\right)_{x} \rightarrow \ldots
\end{aligned}
$$

On the other hand

$$
\begin{aligned}
& \underline{\underline{\mathrm{H}}}^{-i}\left(R j_{*} \underline{\underline{\mathrm{IC}}}_{\bar{p}-2}^{\cdot}\left(L_{n-1}(p) ; \mathbf{Z}_{p}\right)\right)_{x} \cong I H_{i+c-2 n}^{\bar{p}-2}\left(L_{x}^{\prime} ; \mathbf{Z}_{p}\right), \\
& \quad \underline{\underline{\mathrm{H}}}^{-i}\left(\underline{\underline{\mathrm{I}}}_{\bar{p}}^{\cdot}\left(L_{n} ; \mathbf{Z}_{p}\right)\right)_{x} \cong I H_{i+c-2 n}^{\bar{p}}\left(L_{x} ; \mathbf{Z}_{p}\right), \\
& \quad k \geq 2 n-1-p(c),
\end{aligned}
$$


where $c$ is the codimension of the stratum in $L_{n}$ containing $x, L_{x}$ is the link of the stratum in $L_{n}$, and $L_{x}^{\prime}$ is the link of the stratum in $L_{n}(p)$. If we regard $L_{x}$ as $L_{n}$ and construct $L_{n-1}(p)$, then $L_{n-1}(p)$ is equal to $L_{x}^{\prime}$. Thus, by $(3)_{k}, k<n, \underline{\underline{H}}^{-i}\left(\underline{\underline{A}}_{\bar{p}}^{\cdot}\left(\mathbf{Z}_{p}\right)\right)_{x}=0$ when $i<2 n-4$ regardless of the perversity $\bar{p}$. To look at $\underline{\underline{\mathrm{H}}}^{-i}\left(\underline{\underline{A}}_{\bar{p}}^{\cdot}\left(\mathbf{Z}_{p}\right)\right)_{x}$ when $2 n-4 \leq i \leq 2 n-1$, consider the following diagram:

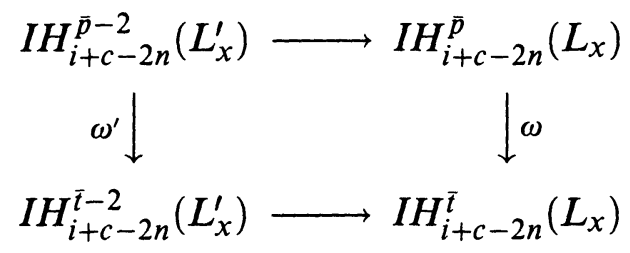

where $\omega$ and $\omega^{\prime}$ are the natural maps. If $i \geq 2 n-4, \omega^{\prime}$ is an isomorphism by definition of intersection homology. Also $\omega$ is an isomorphism if $i \geq 2 n-4$ because $p(4)=2$. Therefore $\underline{\underline{\mathrm{H}}}^{-i}\left(\underline{\underline{\mathrm{A}}}_{\bar{p}}\left(\mathbf{Z}_{p}\right)\right)_{x}$ and $\underline{\underline{\mathrm{H}}}^{-i}\left(\underline{\underline{\mathrm{A}}}_{\bar{t}}^{\bullet}\left(\mathbf{Z}_{p}\right)\right)_{x}$ are isomorphic for all $i$ and $x$, and thus $\underline{\underline{A}}_{\bar{p}}^{\bullet}\left(\mathbf{Z}_{p}\right)=$ $\underline{\underline{A}}_{\bar{t}}^{\bullet}\left(\mathbf{Z}_{p}\right)$ in $D^{b}\left(L_{n}\right)$. Since $L_{n}$ is a normal pseudo-manifold (cf. [GM2; $\S 5.6]), \mathscr{H}_{c}^{-*}\left(L_{n}, \underline{\underline{A}}_{\bar{t}}^{\bullet}\left(\mathbf{Z}_{p}\right)\right) \cong H_{*}\left(L_{n}, L_{n-1} ; \mathbf{Z}_{p}\right)$, where $\mathscr{H}_{c}$ is hypercohomology with compact support. Thanks to the excision property of homology we can calculate $H_{i}\left(L_{n}, L_{n-1} ; \mathbf{Z}_{p}\right)$ easily:

$$
H_{i}\left(L_{n}, L_{n-1} ; \mathbf{Z}_{p}\right)= \begin{cases}\mathbf{Z}_{p}, & i=2 n-1,2 n-2, \\ 0, & \text { otherwise. }\end{cases}
$$

Now $(2)_{n}$ and $(3)_{n}$ follow from the long exact sequence of hypercohomology associated to the triangle.

4. Intersection homology of weighted projective spaces. In this section we determine the intersection homology of weighted projective spaces and the natural maps between them. Let

$$
n_{p}(k)=\alpha_{p, i_{p}(k-1)}-\alpha_{p, i_{p}(k)},
$$

and

$$
l(\bar{p}, n, j, k)=\frac{1}{2} \max \{\min (p(2 k), 2 n-2 j)-\max (0,2 k-2 j-2), 0\}
$$

TheOREM 4.1. Let $\mathbf{P}_{n}=\mathbf{P}_{n}(b)$ be a weighted projective space and $\bar{p}$ be any perversity. Then

$$
I H_{i}^{\bar{p}}\left(\mathbf{P}_{n}\right)= \begin{cases}\mathbf{Z}, & i=2 j, \quad 0 \leq j \leq n \\ 0, & \text { otherwise }\end{cases}
$$


Suppose $\bar{p} \leq \bar{q}$. The natural map $I H_{2 j}^{\bar{p}}\left(\mathbf{P}_{n}\right) \rightarrow I H_{2 j}^{\bar{q}}\left(\mathbf{P}_{n}\right)$ is the multiplication by

$$
\gamma=\prod_{p: \text { prime }} \prod_{k=1}^{n} p^{\left(l\left(\bar{q}^{a}, n, j, k\right)-l\left(\bar{p}^{a}, n, j, k\right)\right) \cdot n_{p}(n-k+1)} .
$$

Proof. Since the link of the stratum at any point in $\mathbf{P}_{n}$ is a pseudolens space, we have $I H_{i}^{\bar{p}}\left(\mathbf{P}_{n}\right) \cong I H_{i}^{\bar{p}^{a}}\left(\mathbf{P}_{n}\right)$ by the same argument as in the proof of Th. 3.1. Thus we may assume $\bar{p}$ is a two-step perversity. In that case we also have the universal coefficient theorem for intersection homology. To prove the first half, we only have to show when $p(4)=2$. To prove the second half, we may assume $\bar{q}=\bar{t}$. Since $\mathbf{P}_{n}$ is a normal pseudo-manifold, $I H_{i}^{0}\left(\mathbf{P}_{n}\right) \cong H^{2 n-i}\left(\mathbf{P}_{n}\right)$ and $I H_{i}^{\bar{t}}\left(\mathbf{P}_{n}\right) \cong H_{i}\left(\mathbf{P}_{n}\right)$, and the map $I H_{2 j}^{\overline{0}}\left(\mathbf{P}_{n}\right) \rightarrow I H_{2 j}^{\bar{t}}\left(\mathbf{P}_{n}\right)$ coincides with the map $\bigcap\left[\mathbf{P}_{n}\right]: H^{2 n-2 j}\left(\mathbf{P}_{n}\right) \rightarrow H_{2 j}\left(\mathbf{P}_{n}\right)$. The latter map has been calculated in $[\mathbf{K}]$ and $[\mathbf{M}]$, and if we translate it into our notation carefully, we see that it is multiplication by

$$
\gamma_{0}=\prod_{p: \text { prime }} \prod_{k=1}^{n} p^{(l(\bar{t}, n, j, k)-l(\overline{0}, n, j, k)) \cdot n_{p}(n-k+1)} .
$$

Combining this result and the universal coefficient theorem, we can assume $p(4)=2$. Let $\mathbf{P}_{n-1}(p)=\bar{X}_{2 n-2 l}(p)$. From now on, the proof proceeds along the same lines as Th. 3.1. We induct on $n$. Consider the triangle

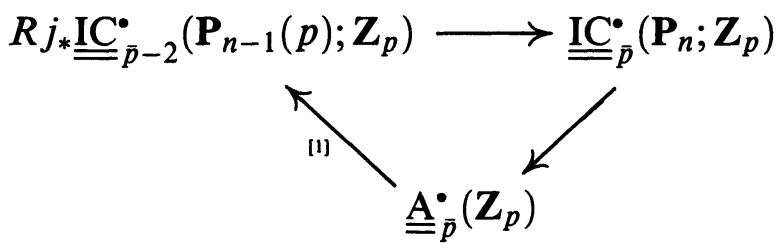

Looking at the link of each point, we conclude $\underline{\underline{\mathrm{A}}}_{\bar{p}}^{\cdot}\left(\mathbf{Z}_{p}\right)=\underline{\underline{\mathrm{A}}}_{\bar{t}}^{\cdot}\left(\mathbf{Z}_{p}\right)$ in $D^{b}\left(L_{n}\right)$. Since

$$
H_{i}\left(\mathbf{P}_{n}, \mathbf{P}_{n-1}(p) ; \mathbf{Z}_{p}\right)= \begin{cases}\mathbf{Z}_{p}, & i=2 n, \\ 0, & \text { otherwise },\end{cases}
$$

we have the following diagram when $0 \leq j \leq n-1$ :

$$
\begin{array}{ccc}
I H_{2 j}^{\bar{p}-2}\left(\mathbf{P}_{n-1}(p) ; \mathbf{Z}_{p}\right) & \cong & \cong H_{2 j}^{\bar{p}}\left(\mathbf{P}_{n} ; \mathbf{Z}_{p}\right) \\
\omega^{\prime} \downarrow & \downarrow \omega \\
I H_{2 j}^{\bar{t}-2}\left(\mathbf{P}_{n-1}(p) ; \mathbf{Z}_{p}\right) \stackrel{\cong}{\longrightarrow} I H_{2 j}^{\bar{\tau}}\left(\mathbf{P}_{n} ; \mathbf{Z}_{p}\right) .
\end{array}
$$


Taking into account that $l(\bar{t}, n, j, k)-l(\bar{p}, n, j, k)=l(\bar{t}-2, n-1, j, k)-$ $l(\bar{p}-2, n-1, j, k)$, this diagram proves the theorem.

CoROllaRY 4.2. Let $R_{i}^{\bar{m}}\left(\mathbf{P}_{n}\right)$ be the peripheral invariant of Goresky and Siegel for the middle perversity (cf. [GS; §9]). Then

$$
R_{2 j}^{\bar{m}}=\mathbf{Z} / \prod_{p: \text { prime }} \prod_{k=1}^{j^{\prime}} p^{n_{p}(n-k+1)},
$$

where $j^{\prime}=\min (j, n-j)$. Thus the middle groups of $\mathbf{P}_{n}(b)$ satisfy Poincaré duality over the integers if and only if $\mathbf{P}_{n}(b)$ is isomorphic to the ordinary projective space.

\section{REFERENCES}

[GM1] M. Goresky and R. MacPherson, Intersection homology theory, Topology, 19 (1980), 135-162.

[GM2] , Intersection Homology II, Inv. Math., 72 (1983), 71-129.

[GS] M. Goresky and P. Siegel, Linking pairing on singular spaces, Comment. Math. Helv., 58 (1983), 96-110.

[K] T. Kawasaki, Cohomology of twisted projective spaces and lens complexes, Math. Ann., 206 (1973), 243-248.

[M] M. Masuda, Cohomology of $S^{1}$-orbit spaces of cohomology spheres and cohomology complex projective spaces, Math. Z., 176 (1981), 405-427.

Received February 2, 1987.

BROWN UNIVERSITY

Providence, RI 02912 


\title{
PACIFIC JOURNAL OF MATHEMATICS
}

\section{EDITORS}

\author{
V. S. VARADARAJAN \\ (Managing Editor) \\ University of California \\ Los Angeles, CA 90024 \\ HERBERT ClEMENS \\ University of Utah \\ Salt Lake City, UT 84112 \\ R. FINN \\ Stanford University \\ Stanford, CA 94305
}

\author{
HERMANN FLASCHKA \\ University of Arizona \\ Tucson, AZ 85721
}

RAMESh A. GANGOLLI University of Washington Seattle, WA 98195

VAUGHAN F. R. JONES University of California

Berkeley, CA 94720

\author{
ROBION KIRBY \\ University of California \\ Berkeley, CA 94720 \\ C. C. MOORE \\ University of California \\ Berkeley, CA 94720 \\ HAROLD STARK \\ University of California, San Diego \\ La Jolla, CA 92093
}

\section{ASSOCIATE EDITORS}

\author{
R. ARENS \\ E. F. BECKENBACH \\ B. H. NEUMANN \\ F. WOLF \\ K. YOSHIDA \\ (1906-1982)

\section{SUPPORTING INSTITUTIONS}

\begin{abstract}
UNIVERSITY OF ARIZONA
UNIVERSITY OF BRITISH COLUMBIA

UNIVERSITY OF CALIFORNIA

MONTANA STATE UNIVERSITY

UNIVERSITY OF NEVADA, RENO

NEW MEXICO STATE UNIVERSITY

OREGON STATE UNIVERSITY
\end{abstract} \\ CALIFORNIA INSTITUTE OF TECHNOLOGY \\ UNIVERSITY OF OREGON \\ UNIVERSITY OF SOUTHERN CALIFORNIA \\ STANFORD UNIVERSITY \\ UNIVERSITY OF HAWAII \\ UNIVERSITY OF TOKYO \\ UNIVERSITY OF UTAH \\ WASHINGTON STATE UNIVERSITY \\ UNIVERSITY OF WASHINGTON
}

The Supporting Institutions listed above contribute to the cost of publication of this Journal, but they are not owners or publishers and have no responsibility for its content or policies.

Mathematical papers intended for publication in the Pacific Journal of Mathematics should be in typed form or offset-reproduced (not dittoed), double spaced with large margins. Please do not use built up fractions in the text of the manuscript. However, you may use them in the displayed equations. Underline Greek letters in red, German in green, and script in blue. The first paragraph must be capable of being used separately as a synopsis of the entire paper. In particular it should contain no bibliographic references. Please propose a heading for the odd numbered pages of less than 35 characters. Manuscripts, in triplicate, may be sent to any one of the editors. Please classify according to the scheme of Math. Reviews, Index to Vol. 39. Supply name and address of author to whom proofs should be sent. All other communications should be addressed to the managing editor, or Elaine Barth, University of California, Los Angeles, California 90024.

There are page-charges associated with articles appearing in the Pacific Journal of Mathematics. These charges are expected to be paid by the author's University, Government Agency or Company. If the author or authors do not have access to such Institutional support these charges are waived. Single authors will receive 50 free reprints; joint authors will receive a total of 100 free reprints. Additional copies may be obtained at cost in multiples of 50 .

The Pacific Journal of Mathematics is issued monthly as of January 1966. Regular subscription rate: $\$ 190.00$ a year (5 Vols., 10 issues). Special rate: $\$ 95.00$ a year to individual members of supporting institutions.

Subscriptions, orders for numbers issued in the last three calendar years, and changes of address should be sent to Pacific Journal of Mathematics, P.O. Box 969, Carmel Valley, CA 93924, U.S.A. Old back numbers obtainable from Kraus Periodicals Co., Route 100, Millwood, NY 10546.

The Pacific Journal of Mathematics at P.O. Box 969, Carmel Valley, CA 93924 (ISSN 0030-8730) publishes 5 volumes per year. Application to mail at Second-class postage rates is pending at Carmel Valley, California, and additional mailing offices. Postmaster: send address changes to Pacific Journal of Mathematics, P.O. Box 969, Carmel Valley, CA 93924.

\section{PUBLISHED BY PACIFIC JOURNAL OF MATHEMATICS, A NON-PROFIT CORPORATION}




\section{Pacific Journal of Mathematics}

\section{Vol. 133, No. 2 \\ April, 1988}

William Charles Bauldry, Attila Mate and Paul Nevai, Asymptotics for solutions of systems of smooth recurrence equations . . . . . . . . . . 209

Ehrhard Behrends, Isomorphic Banach-Stone theorems and isomorphisms which are close to isometries ............................229

Fernanda Maria Botelho, Rotation sets of maps of the annulus .........251

Edward Graham Evans, Jr. and Phillip Alan Griffith, Binomial behavior

of Betti numbers for modules of finite length . ................. 267

Andrei Iordan, Pseudoconvex domains with peak functions at each point of

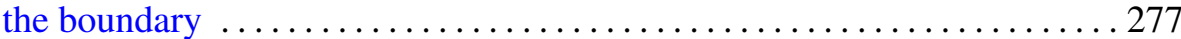

Zyun'iti Iwase, Dehn-surgery along a torus $T^{2}$-knot $\ldots \ldots \ldots \ldots \ldots \ldots . \ldots 289$

Marko Kranjc, Embedding 2-complexes in $\mathbf{R}^{4} \ldots \ldots \ldots \ldots \ldots \ldots \ldots \ldots \ldots$

Aloys Krieg, Eisenstein-series on real, complex, and quaternionic

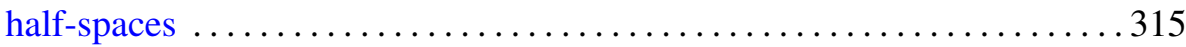

Masato Kuwata, Intersection homology of weighted projective spaces and

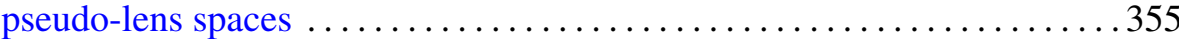

Carl Pomerance, András Sárközy and Cameron Leigh Stewart, On

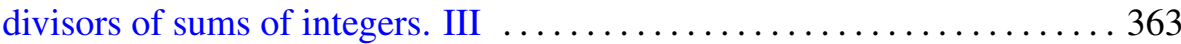

Martin Schechter, Potential estimates in Orlicz spaces ............... 381 